\title{
Precipitation of Stable Icosahedral Phase in Ti-Based Amorphous Alloys*1
}

\author{
Yu Chan Kim ${ }^{1, * 2}$, Jin Man Park ${ }^{1}$, Jin Kyu Lee ${ }^{1, * 3}$, Won Tae Kim² ${ }^{2}$ and Do Hyang Kim ${ }^{1, * 4}$ \\ ${ }^{1}$ Center for Non-crystalline Materials, Department of Metallurgical Engineering, Yonsei University, Seoul 120-749 Korea \\ ${ }^{2}$ Applied Science Division, Chongju University, Chongju 360-764 Korea
}

\begin{abstract}
The crystallization behavior of bulk amorphous Ti-Zr-Be-Cu-Ni alloys has been studied by using differential scanning calorimetry (DSC), $\mathrm{X}$-ray diffractometry (XRD) and transmission electron microscopy (TEM). Detailed thermal analysis showed that Ti-Zr-Be-Cu-Ni amorphous alloys with the wide composition range crystallized through two exothermic reactions followed by one endothermic reaction. At first stage, nanometer scale primary icosahedral phase (I-phase) precipitated from an amorphous matrix and then the remaining amorphous phase crystallized into cubic $\beta$-Ti( $\mathrm{Zr}$ ) phase or hexagonal Laves phase depending on the alloy composition. Finally, I- and $\beta$-Ti( $\mathrm{Zr}$ ) phase or I- and Laves phase mixture transformed into the Laves phase by the high-temperature endothermic reaction, indicating that the I-phase is a thermally stable phase at the lower temperature range. Reversible transformation between the I-phase and Laves phase during cyclic heating and cooling confirmed the thermodynamic stability of the I-phase in Ti-Zr-Be-Cu-Ni system.
\end{abstract}

(Received April 24, 2003; Accepted June 17, 2003)

Keywords: bulk metallic glass, crystallization, stable icosahedral phase, titanium-zirconium-beryllium-copper-nickel

\section{Introduction}

Since the first report of an icosahedral quasicrystal in rapidly solidified $\mathrm{Al}_{84} \mathrm{Mn}_{16},{ }^{1)}$ quasicrystals have been found in several alloy system. The second largest class of quasicrystals, following the Al-based ones, is found in rapidly quenched $\mathrm{Ti}$ alloys. Most of the Ti-based quasicrystals reported to date can be produced only by rapid quenching from the melt, suggesting that they are metastable. It has been reported the stable icosahedral phase (I-phase) in Ti-Zr-Ni alloy and their compositional range is very limited around $\mathrm{Zr}_{41.5} \mathrm{Ti}_{41.5} \mathrm{Ni}_{17}{ }^{2)}$ The stable I-phase appears to be formed by a peritectoid reaction from the hexagonal Laves phase and $\alpha(\mathrm{Ti} / \mathrm{Zr})$ during solidification with a very sluggish reaction rate. $^{3,4)}$ Recently, formation of an I-phase has been reported during crystallization of amorphous $\mathrm{Ti}_{40} \mathrm{Zr}_{28} \mathrm{Cu}_{9} \mathrm{Ni}_{7} \mathrm{Be}_{16}$ alloy. ${ }^{5)}$

Quasicrystals have some unique physical/mechanical properties due to their extra-ordinary crystallographic structure. ${ }^{6,7)}$ Structural applications of quasicrystal materials have intended to use their high stiffness and low friction coefficient. However, most quasicrystals reported so far are thermally metastable and very brittle inhibiting the extensive practical applications of quasicrystals as structural materials. ${ }^{8)}$ One reasonable solution for the practical applications is fabricating composite materials comprising thermally stable quasicrystals. Previous studies show that the crystallization in various bulk metallic glasses (BMGs) is characterized by the appearance of intermediate metastable phases. The formation of I-phase as an intermediate product of the crystallization process in BMGs indicates that there is a

\footnotetext{
${ }^{* 1}$ This Paper was Presented at "International Workshop on nanostructured Metallic materials" which was held 9-12 March, 2003 in Miyagi, Japan

${ }^{* 2}$ Graduate Student, Yonsei University. Present address: Division of Materials Science and Engineering, Korea Institute of Science and Technology (KIST), P.O.Box 131, Cheongryang, Seoul 130-136, Korea.

${ }^{* 3}$ Graduate Student, Yonsei University. Present address: Advanced Material Technology R\&D Center, Nano Material Team, KITECH, 353, CheonAnSi 330-825, Korea

${ }^{* 4}$ Corresponding author: E-mail: dohkim@yonsei.ac.kr
}

structural relationship between the amorphous and quasicrystalline phases. ${ }^{9,10)}$ Since I-phase formed during crystallization of amorphous phase are known to be metastable, studies for structural relationship between the amorphous and quasicrystalline phases and expansions of application area for fabrication of composite materials using quasicrystals have been very limited.

In this letter, we report the precipitation of the stable quasicrystalline phase during crystallization of $\mathrm{Ti}_{33-55^{-}}$ $\mathrm{Zr}_{17-33}-\mathrm{Be}_{7-22}-\mathrm{Cu}_{6-11}-\mathrm{Ni}_{5-10}$ bulk amorphous alloys by a detailed thermal analysis.

\section{Experimental Procedure}

Alloys of nominal composition were prepared by arc melting under an argon atmosphere. Fully amorphous specimens were produced by melt spinning technique to study crystallization behavior. For melt spinning, the alloys were remelted in quartz tubes, followed by ejecting with an over pressure of $35 \mathrm{kPa}$ through a nozzle onto a $\mathrm{Cu}$ wheel rotating with a surface velocity of $40 \mathrm{~m} / \mathrm{s}$. Rod specimens were fabricated by injection casting. The alloys were remelted in quartz tubes, followed by casting into cylindrical cavities of a $\mathrm{Cu}$ mold. Oxygen content measured by PC-136 LECO analyzer was 3000-3500 ppm for both ribbon and injection cast specimens. Carefully controlled heat treatment was performed in a DSC furnace for the amorphous specimens under an Ar atmosphere. Structural change during the heat treatment was studied by using X-ray diffractometry with monochromatic $\mathrm{Cu} \mathrm{K} \alpha$ radiation (Rigaku, RINT2200) and transmission electron microscopy (TEM) (JEOL, 2010F). Crystallization behaviors of the amorphous alloys were studied by differential scanning calorimetry (Perkin Elmer, DSC 7). Exotherms and endotherms were monitored in the DSC during continuous heating from 373 to $873 \mathrm{~K}$ with a heating rate of $0.67 \mathrm{~K} / \mathrm{s}$. 


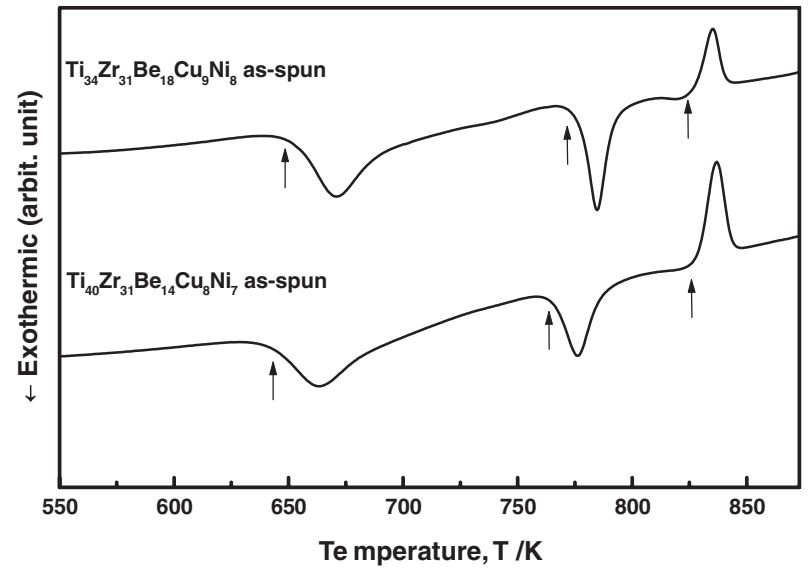

Fig. 1 DSC traces obtained during continuous heating as-melt spun $\mathrm{Ti}_{34} \mathrm{Zr}_{31} \mathrm{Be}_{18} \mathrm{Cu}_{9} \mathrm{Ni}_{8}$ and $\mathrm{Ti}_{40} \mathrm{Zr}_{31} \mathrm{Be}_{14} \mathrm{Cu}_{8} \mathrm{Ni}_{7}$ alloys with a heating rate of $0.67 \mathrm{~K} / \mathrm{s}$.

\section{Results and Discussion}

Figure 1 shows typical DSC spectra obtained during continuous heating as-melt spun $\mathrm{Ti}_{34} \mathrm{Zr}_{31} \mathrm{Be}_{18} \mathrm{Cu}_{9} \mathrm{Ni}_{8}$ and $\mathrm{Ti}_{40} \mathrm{Zr}_{31} \mathrm{Be}_{14} \mathrm{Cu}_{8} \mathrm{Ni}_{7}$ alloys, respectively, with a heating rate of $0.67 \mathrm{~K} / \mathrm{s}$. The DSC traces exhibit a weak endothermic event, corresponding to glass transition, followed by two exothermic reactions and one high temperature endothermic reaction. The appearance of two exothermic events indicates that the amorphous phases crystallized through a two-step process during heating. The high temperature endothermic reaction corresponds to a solid-state transformation of a crystallization product into high temperature phase. The initial and final phases are identified in Fig. 2. Figure 2(a) shows a typical XRD traces obtained from the heat treated $\mathrm{Ti}_{34} \mathrm{Zr}_{31} \mathrm{Be}_{18} \mathrm{Cu}_{9} \mathrm{Ni}_{8}$ and $\mathrm{Ti}_{40} \mathrm{Zr}_{31} \mathrm{Be}_{14} \mathrm{Cu}_{8} \mathrm{Ni}_{7}$ ribbon specimens. Both as-melt spun specimens show a broad halo pattern, characteristic of the amorphous structure (not shown). The specimen heated up to the first exothermic reaction, shows broad diffraction peaks superimposed on a halo pattern, indicating a partial crystallization takes place in the first exothermic reaction. The broad diffraction peaks $\mathrm{Ti}_{34} \mathrm{Zr}_{31} \mathrm{Be}_{18} \mathrm{Cu}_{9} \mathrm{Ni}_{8}$ and $\mathrm{Ti}_{40} \mathrm{Zr}_{31} \mathrm{Be}_{14} \mathrm{Cu}_{8} \mathrm{Ni}_{7}$ alloys can be analyzed into the I-phase with a quasi-lattice constant of $a_{\mathrm{Q}}=0.516 \mathrm{~nm}$ and $0.515 \mathrm{~nm}$, respectively. The quasicrystalline particle size estimated from the diffraction peak widths was about $8.8 \mathrm{~nm}$. The XRD trace from the specimen heated to the second exothermic reaction, exhibits several sharp diffraction peaks. All the diffraction peaks could be analyzed into a mixture of hexagonal Laves phase with lattice constants of $a=0.53$ and $c=0.86 \mathrm{~nm}$ and the I-phase for $\mathrm{Ti}_{34} \mathrm{Zr}_{31} \mathrm{Be}_{18} \mathrm{Cu}_{9} \mathrm{Ni}_{8}$ alloy and a mixture of the cubic $\beta$ $\mathrm{Ti}(\mathrm{Zr})$ phase with a lattice constant of $a=0.34 \mathrm{~nm}$ and Iphase for $\mathrm{Ti}_{40} \mathrm{Zr}_{31} \mathrm{Be}_{14} \mathrm{Cu}_{8} \mathrm{Ni}_{7}$ alloy. The XRD trace from $\mathrm{Ti}_{40} \mathrm{Zr}_{31} \mathrm{Be}_{14} \mathrm{Cu}_{8} \mathrm{Ni}_{7}$ alloy heated to $800 \mathrm{~K}$ is similar to that from the sample heated to $723 \mathrm{~K}$, except for the change in peak intensity. The change in the relative intensity of the two main peaks can be explained by the superposition of the diffraction peaks from I-phase and cubic $\beta$-Ti( $\mathrm{Zr})$ phase. Also it can be noticed that the diffraction peaks corresponding to the I-phase became sharp, resulting from growth of the


Fig. 2 (a) XRD traces obtained from $\mathrm{Ti}_{34} \mathrm{Zr}_{31} \mathrm{Be}_{18} \mathrm{Cu}_{9} \mathrm{Ni}_{8}$ ribbon specimens heated to 703,803 and $873 \mathrm{~K}$ and $\mathrm{Ti}_{40} \mathrm{Zr}_{31} \mathrm{Be}_{14} \mathrm{Cu}_{8} \mathrm{Ni}_{7}$ ribbon specimens heated to 723,800 and $873 \mathrm{~K}$ (b) typical bright field TEM image, (c) an electron diffraction pattern with schematic analysis and (d) the high resolution TEM image showing the five fold symmetry of quasicrystal obtained from the $\mathrm{Ti}_{40} \mathrm{Zr}_{31} \mathrm{Be}_{14} \mathrm{Cu}_{8} \mathrm{Ni}_{7}$ alloy heated to $723 \mathrm{~K}$.

I-phase formed in the first exothermic reaction, and shifted to lower angle direction, suggesting the occurrence of compositional partitioning in the I-phase during heating. The XRD trace from the specimen heated to $873 \mathrm{~K}$, corresponding to the high temperature endothermic reaction, showed several diffraction peaks. All the diffraction peaks could be analyzed into the Laves phase, suggesting the previously formed quasicrystalline phase transformed into the Laves phase. In case of the $\mathrm{Ti}_{40} \mathrm{Zr}_{31} \mathrm{Be}_{14} \mathrm{Cu}_{8} \mathrm{Ni}_{7}$ alloy small amount of the $\beta$ $\mathrm{Ti}(\mathrm{Zr})$ phase still remained after heating up to $873 \mathrm{~K}$. The Iphase is stable at low temperature and transformed into a Laves phase at high temperature through the endothermic reaction. Figures 2 (b) $\sim(d)$ show, respectively, typical bright field TEM image, an electron diffraction pattern with schematic analysis and the high resolution TEM image showing the five fold symmetry of quasicrystal obtained from the $\mathrm{Ti}_{40} \mathrm{Zr}_{31} \mathrm{Be}_{14} \mathrm{Cu}_{8} \mathrm{Ni}_{7}$ alloy heated to $723 \mathrm{~K}$. The SADP showed several ring patterns, superimposed on a dim halo pattern. The distribution of ring patterns corresponded to the I-phase, in agreement with the diffraction peaks on XRD pattern and the high resolution TEM image taken along the five fold symmetry, indicating the formation of I-phase by primary crystallization process. Typical size of the I-phase particle was about $10 \sim 15 \mathrm{~nm}$. Similar microstructure was observed in the $\mathrm{Ti}_{34} \mathrm{Zr}_{31} \mathrm{Be}_{18} \mathrm{Cu}_{9} \mathrm{Ni}_{8}$ alloy after the first 
exothermic reaction. The formation of $\beta$-Ti( $\mathrm{Zr})$ and Laves phases after second endothermic reaction was confirmed by TEM analysis (not shown).

$\mathrm{Ti}_{34} \mathrm{Zr}_{31} \mathrm{Be}_{18} \mathrm{Cu}_{9} \mathrm{Ni}_{8}$ and $\mathrm{Ti}_{40} \mathrm{Zr}_{31} \mathrm{Be}_{14} \mathrm{Cu}_{8} \mathrm{Ni}_{7}$ amorphous alloys crystallized through a two step exothermic reaction. Nanoscaled primary I-phase precipitated from an amorphous matrix and then the remaining amorphous phase crystallized into the cubic $\beta$ - $\mathrm{Ti}(\mathrm{Zr})$ phase for $\mathrm{Ti}_{40} \mathrm{Zr}_{31} \mathrm{Be}_{14} \mathrm{Cu}_{8} \mathrm{Ni}_{7}$ alloy and into the hexagonal Laves phase for $\mathrm{Ti}_{34} \mathrm{Zr}_{31} \mathrm{Be}_{18} \mathrm{Cu}_{9} \mathrm{Ni}_{8}$ alloy. The I-phase transformed into the Laves phase, which is hexagonal polytetrahedral Frank-Kasper phase, ${ }^{11)}$ at high temperature through an endothermic reaction, which is suggesting that the I-phase is a stable phase at lower temperature. Formation of I-phase during crystallization has been reported in $\mathrm{Zr}$-based, ${ }^{12)} \mathrm{Al}$-based ${ }^{13)}$ and Ti-based ${ }^{14)}$ amorphous alloys. However all these are known to be metastable. In order to confirm the solid state transformation, cyclic heating and cooling experiment was performed. Figure 3(a) shows DSC traces obtained during the cyclic heating and cooling the $\mathrm{Ti}_{40} \mathrm{Zr}_{31} \mathrm{Be}_{14} \mathrm{Cu}_{8} \mathrm{Ni}_{7}$ amorphous alloy with a heating and cooling rate of $0.167 \mathrm{~K} / \mathrm{s}$. Lower heating and cooling rate was applied due to the limit in cooling rate in the temperature range of $600 \sim 873 \mathrm{~K}$. DSC trace during the first crystallization is basically same as Fig. 1 except for the shift of peak temperatures to lower temperature region due to the lower heating rate. Again we can notice the high temperature endothermic reaction during heating and exothermic reaction during cooling. After the first cyclic heating and cooling,

(a)
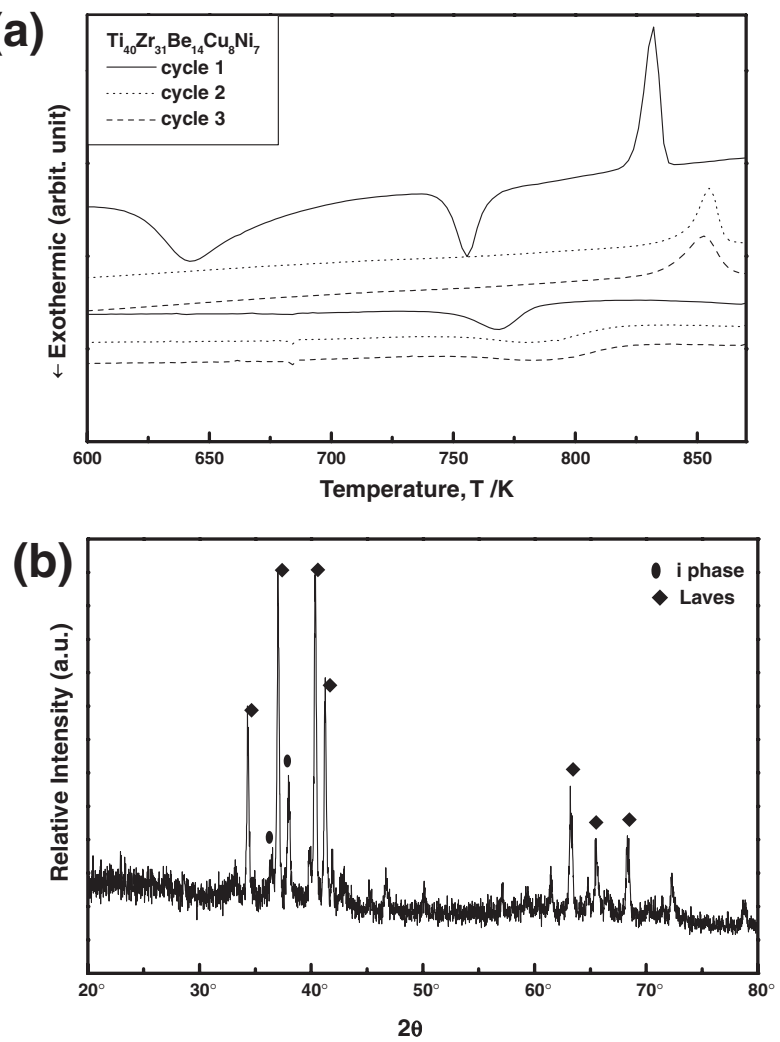

Fig. 3 (a) DSC traces obtained during cyclic heating and cooling the amorphous $\mathrm{Ti}_{40} \mathrm{Zr}_{31} \mathrm{Be}_{14} \mathrm{Cu}_{8} \mathrm{Ni}_{7}$ alloy with a heating and cooling rate of $0.167 \mathrm{~K} / \mathrm{s}$ (b) XRD traces obtained from $\mathrm{Ti}_{40} \mathrm{Zr}_{31} \mathrm{Be}_{14} \mathrm{Cu}_{8} \mathrm{Ni}_{7}$ ribbon specimens, heated to $873 \mathrm{~K}$ and then cooled down to $673 \mathrm{~K}$ with a cooling rate of $0.167 \mathrm{~K} / \mathrm{s}$ followed by holding 1 hour at $673 \mathrm{~K}$. exothermic peaks corresponding to the crystallization disappeared and only high temperature endothermic peak during heating cycle and the exothermic peak during cooling cycle survived. After the second cyclic heating and cooling, both the heating endotherms and cooling exotherms reach steady states with onset temperatures of 842 and $812 \mathrm{~K}$, respectively. DSC traces obtained during the cyclic heating and cooling the $\mathrm{Ti}_{34} \mathrm{Zr}_{31} \mathrm{Be}_{18} \mathrm{Cu}_{9} \mathrm{Ni}_{8}$ amorphous alloy with a heating and cooling rate of $0.167 \mathrm{~K} / \mathrm{s}$ was analogous to those of $\mathrm{Ti}_{40} \mathrm{Zr}_{31} \mathrm{Be}_{14} \mathrm{Cu}_{8} \mathrm{Ni}_{7}$ alloy (not shown). To confirm the formation of the I-phase during cooling, the amorphous $\mathrm{Ti}_{34} \mathrm{Zr}_{31} \mathrm{Be}_{18} \mathrm{Cu}_{9} \mathrm{Ni}_{8}$ alloy was heated to $873 \mathrm{~K}$, and then cooled down to $673 \mathrm{~K}$ with a cooling rate of $0.167 \mathrm{~K} / \mathrm{s}$ followed by holding 1 hour at $673 \mathrm{~K}$. As can be seen in the XRD trace (Fig. 3(b)), the specimen consisted of a mixture of I-phase and Laves phase. Therefore, the present results clearly show that the stable I- and Laves phases transform reversibly in the solid state during heating and cooling. It has been reported that the stable I-phase in $\mathrm{Zr}$-Ti-Ni alloy is very limited in compositional range around $\mathrm{Zr}_{41.5} \mathrm{Ti}_{41.5} \mathrm{Ni}_{17}{ }^{2)}$ The formation of the stable I-phase in this study may indicate that the addition of Be enhanced the stability of the I-phase, which was observed in Al-based quasicrystalline phase. ${ }^{15,16)}$

Figure 4 shows a schematic diagram showing the composition range for the formations of the stable I-phase in the Ti$\mathrm{Zr}-\mathrm{Be}-\mathrm{Ni}-\mathrm{Cu}$ alloy system. The result indicates that in-situ composites consisting of stable I-phase embedded in an amorphous matrix can be fabricated by heat treatment of fully amorphous phase. The formation of nano scale I-phase in the Ti-Zr-Be-Ni-Cu amorphous matrix enhances the strength without losing plastic elongation during compression test. ${ }^{17)}$ Since the Ti-Zr-Be-Ni-Cu alloys in the composition range shown in Fig. 4 exhibit high glass forming ability (Fully amorphous rod specimens with the diameter of $5 \mathrm{~mm}$ can be fabricated by injection casting), ${ }^{17)}$ the precipitation of stable I-phase in the amorphous matrix can be utilized effectively in improving the property of the Ti-based BMGs.

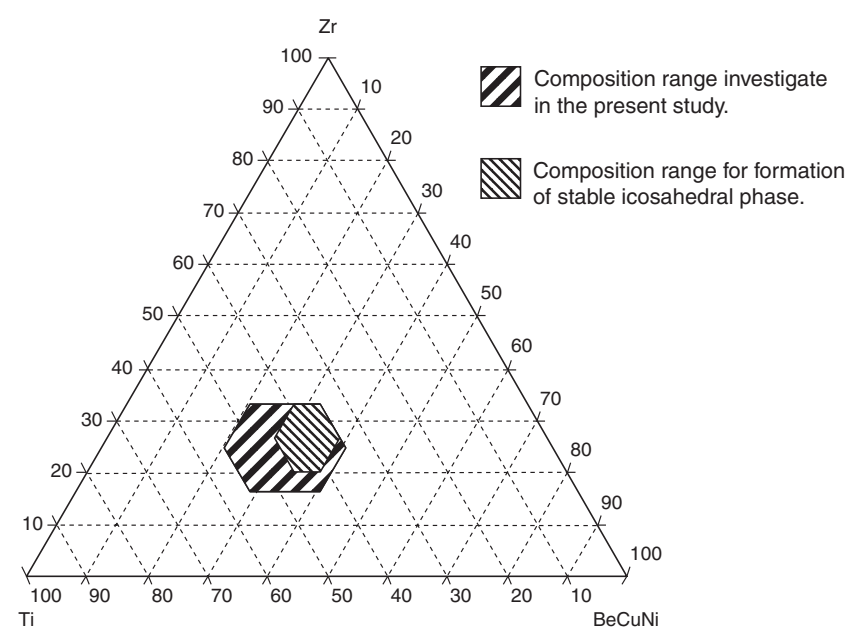

Fig. 4 Schematic diagram showing the composition range for the formation of stable I-phase in Ti-Zr-Be-Cu-Ni alloy system. 


\section{Summary}

The Ti-Zr-Be-Cu-Ni amorphous alloys with the wide composition range crystallized through two exothermic reactions followed by one endothermic reaction. At first stage, nanometer scale primary I-phase precipitated from an amorphous matrix and then the remaining amorphous phase crystallized into cubic $\beta$-Ti( $\mathrm{Zr})$ phase or hexagonal Laves phase. Finally, I- and $\beta$-Ti(Zr) phase or I- and Laves phase mixture transformed into the Laves phase by the hightemperature endothermic reaction, indicating that the I-phase is a thermally stable phase at the lower temperature range. Reversible transformation between the I-phase and Laves phase takes place with heating endothermic reaction and cooling exothermic reaction during cyclic heating and cooling. In-situ composites consisting the stable I-phase embedded in the amorphous matrix can be fabricated by heat treatment of the bulk amorphous $\mathrm{Ti}-\mathrm{Zr}-\mathrm{Be}-\mathrm{Cu}-\mathrm{Ni}$ alloys.

\section{Acknowledgements}

This work was supported by Creative Research Initiatives of Korea Ministry of Science and Technology.

\section{REFERENCES}

1) D. Shechtman, I. A. Blech, D. Gratias and J. W. Cahn: Phys. Rev. Lett. 53 (1984) 1951-1953.

2) K. F. Kelton, W. J. Kim and R. M. Stroud: Appl. Phys. Lett. 70 (1997) 3230-3232.

3) J. P. Davis, E. H. Mahzoub, J. M. Simmons and K. F. Kelton: Mater. Sci. Eng. A294-296 (2000) 104-107.

4) S. Yi and D. H. Kim: J. Mater. Res. 15 (2000) 892-897.

5) Y. C. Kim, J. M. Park, J. K. Lee, D. H. Bae, W. T. Kim and D. H. Kim: Mater. Sci Eng. A, accepted (2003).

6) Y. K. Kovneristyi, V. N. Chebotnikov and Y. E. Mukhina: Russ. Metall. 6 (1997) 92-97.

7) R. Nicula, A. Jianu, A. R. Biris, D. Lupu, R. Manaila, A. Devenyi, C. Kumpf and E. Burkel: Eur. Phys. J. B. 3 (1998) 1-9.

8) U. Köster, W. Kiu, H. Leibertz and M. Michel: J. Non-Crystall. Solids 153-154 (1993) 446-452.

9) U. Köster, J. Meinhardt, S. Roos and R. Busch: Mater. Sci Eng. A226228 (1997) 995-998.

10) M. W. Chen, T. Zhang, A. Inoue and T. Sakurai: Appl. Phys. Lett. 75 (1999) 1697-1699.

11) F. C. Frank and J. S. Kasper: Acta Crystallogr. 11 (1959) 483-499.

12) J. K. Lee, G. Choi, W. T. Kim and D. H. Kim: Appl. Phys. Lett. 77 (2000) 978-980.

13) A. Inoue: Acta Mater. 48 (2000) 279-306.

14) L. Wang and A. Inoue: Mater. Trans. 42 (2001) 2637-2640.

15) S. M. Lee, B. H. Kim, D. H. Kim and W. T. Kim: J. Mater. Res. 16 (2001) 1535-1540.

16) S. H. Kim, G. S. Song, E. Fleury, K. Chattoradhyay, W. T. Kim and D. H. Kim: Philos. Mag. 82 (2002) 1495-1508.

17) J. M. Park, Y. C. Kim, J. K. Lee, W. T. Kim and D. H. Kim: J. NonCrystall. Solids (2003) to be submitted. 